\title{
Study on the takeoff landing number of emergency rescue aircraft demand after earthquake
}

\author{
Zhang xiuyan $^{1,2}$ and Chi hong ${ }^{1}$ \\ ${ }^{1}$ University of Chinese Academy of Sciences, Institutes of Science and Development, Beijing, China, 100190 \\ ${ }^{2}$ Civil Aviation University of China, Economics and Management College, Tianjin, China, 300300
}

\begin{abstract}
Due to the lack of information after earthquake, the demand for takeoff landing number of emergency rescue aircraft is not clear. The model for takeoff landing number of emergency rescue aircraft demand after earthquake is constructed. Firstly, the total task amount of emergency rescue is determined according to the number of injured persons and the number of victims after the earthquake. Then, according to the damage degree of the ground roads in the earthquake area, the amount of aviation emergency rescue mission is determined. Finally, based on the information of emergency rescue aircraft fleet, the actual takeoff landing number of emergency rescue aircraft is calculated. The rationality of the model is verified by the data of 5 actual earthquake events from 2008 , to provide guidance for effective aviation emergency rescue after earthquake.
\end{abstract}

\section{INTRODUCTION}

China is located between the two major earthquake belts of the Pacific earthquake belt and the Eurasian earthquake belt, which are squeezed by the Pacific plate, the India plate and the Philippines Sea plate. The earthquake source is shallow, the frequency is high, the magnitude is large and the distribution is wide. From the Wenchuan earthquake in 2008, the Ya'an earthquake in 2013 to the Jiuzhaigou earthquake in 2017, serious loss of life and property was caused to our country. Emergency rescue work after earthquake is key to reduce earthquake losses. With the progress of the society and the development of the economy, the aviation emergency rescue force is increasingly involved in the emergency rescue work after earthquake, and it has become an organic supplement to the ground emergency rescue force. Compared with other traditional rescue methods, the aviation emergency rescue force has the characteristics of flexible, rapid and efficient and not restricted by geographical space. It plays a more and more important role in the emergency work after earthquake.

However, we could not quickly and accurately obtain information about casualties, housing and road damage after earthquake, which led to the failure to determine the specific needs of aviation emergency rescue force for disaster area immediately. The indistinct demand directly lead to the mismatch between the dispatched aviation emergency rescue force and the actual rescue needs. During emergency rescue after earthquake, time is life. If the dispatching emergency rescue force is lower than the actual demand, it will increase the rescue time and reduce the rescue efficiency. Otherwise, it will cause the waste of rescue resources and increase the command load of rescue site.

At present, most of the research on emergency demand after earthquake is focused on the demand of relief materials, namely how to calculate the needed relief materials according to the basic information obtained after earthquake ${ }^{[1-5]}$. Based on decades of earthquake data, Nie summed up the relationship between the demand of more than 80 kinds of materials and the number of victims ${ }^{[6]}$. Guo constructed the BP network using 6 factors including earthquake occurrence time, magnitude and so on as the input data, trained the network according to the actual data of 16 earthquakes, and finally completed the prediction of the number of casualties ${ }^{[7]}$. Lu uses the IDF-IKF method to study the quantitative relationship between number of survival and material demand ${ }^{[8]}$. $\mathrm{Xu}$ used time series method to predict the change rule of material demand after the earthquake ${ }^{[9]}$. The literature about emergency rescue force after earthquake is usually focused on how to allocate task for rescue forces and to plan rescue routes under the assumption that the demand is known ${ }^{[10-14]}$. Du studied the optimal allocation of ambulance helicopters during the flow process of the wounded in the tent hospital ${ }^{[15]}$. Liu studied the transportation plan for sending relief personnel and injured persons from different transfer points by helicopters according to the different demand levels of disaster areas ${ }^{[16]}$. On the basis of the daily demand for various materials of each affected area, Zdamar has studied how to complete the delivery of 
materials from the supply point to the demand point by using various modes of transportation ${ }^{[17]}$. Lu studied helicopter scheduling problem after earthquake by building a bi-level multi-objective programming model [18].

Few literature is related to the needs of the rescue force. The demand for emergency rescue force after earthquake is still relied on expert experience, without mature method yet. Therefore, it is necessary to study the influence factors of the emergency rescue task after earthquake, and build the takeoff landing number model of the emergency rescue aircraft after earthquake, so as to provide the accurate demand information for the follow-up emergency rescue aircraft scheduling and improve the efficiency of the rescue.

\section{Study framework}

According to the literatures mentioned above, the key factor to determine the size of relief needs is the loss information caused by earthquakes. Similarly, the factors determining the demand for emergency rescue aircraft after earthquakes are also the loss information after earthquakes, including (1) the number of injured people and the total number of affected people after earthquakes: determine the total amount of emergency rescue tasks; (2) the degree of damage to the ground roads after earthquake: determine the level of demand for aviation emergency rescue forces.

A model for calculating the takeoff landing number of aircraft after earthquake is constructed, which propose a quantitative method for calculating the takeoff landing number of emergency rescue aircraft based on the demand information, as shown in Figure 1.

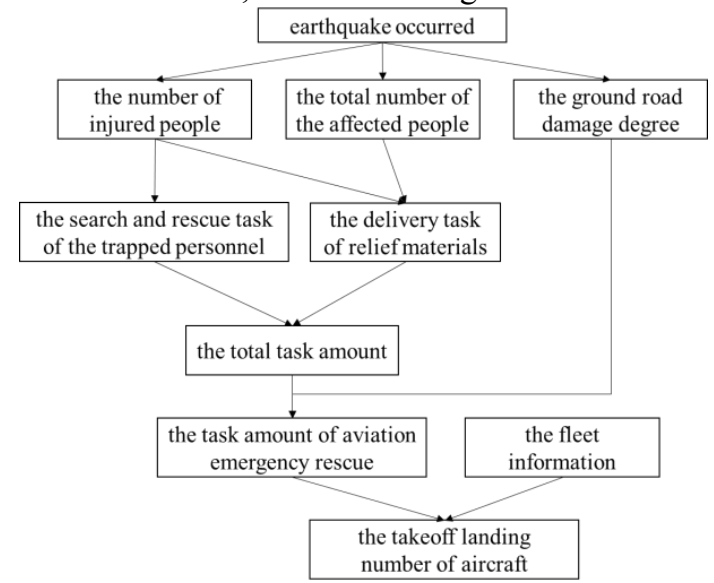

Figure 1. The study framework

\section{The takeoff landing number model of emergency rescue aircraft demand after earthquake}

The aviation emergency rescue task A after earthquake depends on the total rescue task $\mathrm{T}$ and the demand degree of the aviation emergency rescue work, that is the damage degree $r$ of the ground road in the earthquake area. But even all the ground roads are not damaged, there will be certain aviation emergency rescue demand due to timeliness requirements, which is the datum value of aviation emergency rescue after earthquake $\delta$.

Accordingly, the takeoff landing number model of emergency rescue aircraft demand after earthquake is put forward, as follows:

$$
\mathbf{A}=\frac{s_{d}}{s_{e}}\left[\boldsymbol{n}_{w} / \boldsymbol{\alpha}+\left(\boldsymbol{\mu}_{l} * \boldsymbol{n}_{e}+\boldsymbol{\mu}_{m} * \boldsymbol{n}_{w}\right) / \boldsymbol{\beta}\right]+\boldsymbol{\delta}
$$

$\boldsymbol{S}_{\boldsymbol{d}}$ : The damage range of the road;

$\boldsymbol{S}_{\boldsymbol{e}}$ : The scope of the earthquake wave;

$\boldsymbol{n}_{\boldsymbol{w}}$ : The number of injured people;

$\boldsymbol{n}_{\boldsymbol{e}}$ : The total number of the affected people;

$\boldsymbol{\mu}_{\boldsymbol{l}}$ : The coefficient of living material, meaning the average tonnage of living materials needed for each person;

$\boldsymbol{\mu}_{\boldsymbol{m}}$ : The coefficient of medical material, meaning the average tonnage of medical materials required for each injured person;

$\boldsymbol{\alpha}$ : The average number of passengers of the rescue aircraft;

$\boldsymbol{\beta}$ :The average tonnage of the rescue aircraft.

\subsection{Calculation of total task amount of emergency rescue after earthquake}

Because of the difficulty in defense against earthquake disasters beforehand, the requirement for rescue afterwards is relatively high. In the event of an earthquake, the most important thing is to save people. We must rescue the trapped personnel with limited resources as soon as possible. The second is to provide necessary materials for people in earthquake area to ensure they can survive. Generally speaking, the two most important things in the emergency rescue process after earthquake are search and rescue of trapped personnel and relief supplies. Search and rescue trapped personnel are mainly in the initial rescue phase after the earthquake, searching for the injured and trapped people in the earthquake area and sending them to a nearby hospital or emergency medical center. The delivery of relief materials refers to the provision of the necessary materials, including living materials and medical materials, to the personnel in the earthquake area, which usually runs through the whole process of emergency rescue. The total task $\mathrm{T}$ of emergency rescue after earthquake can be expressed as follows:

$$
\mathrm{T}=T_{S}+T_{P}
$$

$T_{S}$ is the search and rescue task of the trapped personnel; $T_{P}$ is the delivery task of relief materials.

In general, the higher the magnitude, the greater the intensity, the higher the population density in the earthquake area, the more the number of disaster victims is and the greater the search and rescue task $T_{S}$ of the trapped personnel is. The amount of relief supplies, that is, the amount of living materials and medical materials needed in the earthquake area, directly depends on the number of affected population and the number of injured population in the earthquake area. That is to say, the 
search and rescue task of the trapped personnel $T_{S}$ and the delivery task of relief materials $T_{P}$ are determined by the number of the affected population, so the total task $\mathrm{T}$ of emergency rescue after earthquake can be estimated by the number of the affected population in the earthquake area.

After the earthquake, we need to rescue immediately according to the basic information such as magnitude, intensity and the number of injured persons, so as to minimize the loss of casualties. It is assumed that, the basic information including the number of injured people $n_{w}$, the total number of the affected people $n_{e}$, and the material demand can be obtained immediately after earthquake, and updated in real time with the development of the earthquake. Then the total task amount $\mathrm{T}$ of emergency rescue after earthquake can be calculated directly according to $n_{w}$ and $n_{e}$, and the calculation formula is as follows

$$
\begin{gathered}
T_{S}=n_{w} \\
T_{P}=\mu_{l} * n_{e}+\mu_{m} * n_{w}
\end{gathered}
$$

The search and rescue task of the trapped personnel $T_{S}$ refers to the number of people who need to be transported out of the earthquake area, directly got from the number of injured people $n_{w}$. The delivery task of relief materials $T_{P}$ refers to the total tonnage of relief materials that need to be transported to the earthquake area, including living materials and medical materials.

\subsection{Calculation of task amount of aviation emergency rescue after earthquake}

The biggest advantage of air transportation is fast speed. The longer the distance is, the more time the air transportation can save, the more obvious the characteristics are. The destruction of the road after earthquake will not affect the route condition. It is an essential transportation mode for the emergency rescue after earthquake. The greater the degree of damage to the ground roads after earthquake, the higher the demand for aviation emergency rescue forces is. The aviation emergency rescue task after earthquake A increases while $r$ increasing and vice versa.

Because the structure of ground road is a space network which has a long distribution in space, the damage degree will be affected by different factors such as earthquake intensity. After the large-scale earthquake disaster, the ground road is the main escape channel of the disaster area and the input channel of the rescue materials. It plays a very important role in the emergency rescue of the earthquake disaster. After the earthquake, the ground roads will be damaged to varying degrees, resulting in reduced road capacity, and personnel escape and rescue supplies are affected.

Generally speaking, the ground roads are damaged in large area or even interrupted during the early stage after earthquake, and $r$ is close to 1 . In the mid-term of earthquake rescue, the ground roads gradually recover, but they can be damaged by the aftershocks again, so $r$ is spirally reduced. During the recovery period, the ground roads are basically completely restored, and $\mathrm{r}$ is close to 0 .

The demand for emergency materials has a very strong timeliness, so we need to analyze and judge the degree of road damage at the first time. The higher the road damage, the more difficult the ground vehicles is, even impassable, so in order to implement the rescue as soon as possible, it is necessary to transport the wounded and materials first by the rescue aircraft.

After earthquake, it is usually impossible to know the extent of the road damage in real time and accurately, but it is possible to know about the scope of the earthquake wave and the damage range of the road in this area. Then the ground road damage degree $r$ can be equivalent to the road damage ratio within the scope of the disaster.

$$
\mathrm{r}=S_{d} / S_{e}
$$

Then the search and rescue task of the trapped personnel by aircraft $A_{S}$ and the delivery task of relief materials by aircraft $A_{P}$ can be calculated separately from the following formula:

$$
\begin{aligned}
& A_{S}=r * T_{S} \\
& A_{P}=r * T_{P}
\end{aligned}
$$

\subsection{Calculation of the takeoff landing number of emergency rescue aircraft}

The calculation of the takeoff landing number of emergency rescue aircraft bases on the search and rescue task of the trapped personnel by aircraft $A_{S}$ and the delivery task of relief materials by aircraft $A_{P}$. Assuming that the size and type of rescue aircraft are known, the average number of passengers $\alpha$ and the average tonnage $\beta$ of the rescue aircraft can be calculated. The takeoff landing number of emergency rescue aircraft $A$ can be calculated from the following formula:

$$
\mathrm{A}=A_{S} / \alpha+A_{P} / \beta+\delta
$$

Considering that a part of the aircraft that carries out the task of searching and rescuing the trapped personnel can carry out the mission of relief supplies at the same time, the actual needs of the aviation emergency rescue force should be within the following range:

$$
\left[\max \left(A_{S} / \alpha, A_{P} / \beta\right)+\delta, A\right]
$$

\section{Example analysis}

It is more and more common for aviation emergency rescue forces to participate in emergency rescue work after earthquake since the Wenchuan earthquake in 2008. Therefore, considering the data verifiability, the Wenchuan earthquake in 2008, the Ya'an earthquake in 2013, the Dingxi earthquake in Gansu in 2013, the Xinjiang earthquake in 2014, and the Jiuzhaigou earthquake in 2017 are used as an example to carry out the model verification and analysis. Specific data is shown in Table 1. 
Table 1. Table of earthquake case data

\begin{tabular}{|l|c|c|c|c|}
\hline \multicolumn{1}{|c|}{ Earthquake name } & $\begin{array}{c}\text { The injured } \\
\text { people } \mathbf{n}_{\mathbf{w}}\end{array}$ & $\begin{array}{c}\text { The affected } \\
\text { people } \mathbf{n}_{\mathbf{e}}\end{array}$ & $\begin{array}{c}\text { The damage } \\
\text { degree of road } \mathbf{~ r}\end{array}$ & $\begin{array}{c}\text { The actual takeoff } \\
\text { landing number }\end{array}$ \\
\hline the Wenchuan earthquake in 2008 & 374643 & 6437000 & 0.95 & 450 \\
\hline the Ya'an earthquake in 2013 & 11470 & 383000 & 0.9 & 53 \\
\hline the Dingxi earthquake in Gansu in 2013 & 582 & 440000 & 0.1 & 20 \\
\hline the Xinjiang earthquake in 2014 & 0 & 7838 & 0.8 & 2 \\
\hline the Jiuzhaigou earthquake in 2017 & 525 & 176492 & 0.9 & 127 \\
\hline
\end{tabular}

Data source: China earthquake Information Network

The purpose of this paper is to calculate the total demand for delivering materials, so it is not necessary to distinguish the types of goods and materials. According to the corresponding relationship between the demand for all kinds of materials after earthquake and the number of affected people by $\mathrm{Nie}{ }^{[6]}$, the value of $\mu_{l}$ is $2 \mathrm{~kg}$ per person, and the value of $\mu_{m}$ is $1 \mathrm{~kg}$ per person. Based on the type of the rescue aircraft participating in the five earthquake, the average number of passengers $\alpha$ was determined to be 10 persons per frame, and the average tonnage $\beta$ was 2 tons per frame. The datum value of aviation emergency rescue after earthquake $\delta$ was 5 . The calculating result is shown in Table 2.

Table 2. Comparison table of model calculation results

\begin{tabular}{|l|c|c|}
\hline \multicolumn{1}{|c|}{ Earthquake name } & $\begin{array}{c}\text { Actual } \\
\text { result }\end{array}$ & $\begin{array}{c}\text { Calculating } \\
\text { result }\end{array}$ \\
\hline $\begin{array}{l}\text { the Wenchuan earthquake } \\
\text { in 2008 }\end{array}$ & 450 & {$[6298,41889]$} \\
\hline $\begin{array}{l}\text { the Ya'an earthquake in } \\
2013\end{array}$ & 53 & {$[1037,1387]$} \\
\hline $\begin{array}{l}\text { the Dingxi earthquake in } \\
\text { Gansu in 2013 }\end{array}$ & 20 & {$[49,55]$} \\
\hline $\begin{array}{l}\text { the Xinjiang earthquake } \\
\text { in 2014 }\end{array}$ & 2 & {$[11,11]$} \\
\hline $\begin{array}{l}\text { the Jiuzhaigou earthquake } \\
\text { in 2017 }\end{array}$ & 127 & {$[111,143]$} \\
\hline
\end{tabular}

From the above results, it can be seen that the actual takeoff landing number of rescue aircraft in 2008 Wenchuan earthquake is quite different from the calculation results. This is because the aviation emergency rescue force had not yet been universally involved in emergency rescue work after earthquake, and the rescuing aircraft did not meet the needs of the rescue. But after 2008, with the continuous development of the general aviation industry, the emergency rescue force of civil aviation is becoming more and more perfect. Many general aviation enterprises even take the initiative to participate in earthquake rescue. Therefore, the aircraft involved in the rescue gradually improved in meeting the needs of rescue. Until the Jiuzhaigou earthquake in 2017 , the actual rescue takeoff landing number had fallen within the rescue requirement interval, basically meeting the needs of rescue.

\section{Conclusions}

By analyzing the main task demand of emergency rescue after earthquake and the influence factors of the emergency rescue demand for aviation, this paper calculates the takeoff landing number of rescue aircraft after earthquake, and draws the following conclusions:

(1) The number of injured people after earthquake and the number of affected people in the earthquake area are the key factors for determining the amount of emergency rescue tasks

(2) The damage degree to the ground roads in the earthquake area is the key factor for determining the demand for the aviation emergency rescue force after earthquake.

(3) The actual takeoff landing number of aircraft involved in rescue is different with the type of rescue aircraft, which is expressed using interval representation. How to dispatch aircraft belongs to mission assignment problem of rescue aircraft, which is also the research direction of the next step. That is, how to optimize the rescue aircraft scheduling after determining the demand for aviation emergency rescue forces after earthquake, so as to improve the efficiency of rescue.

(4) In the case analysis, the input data of the model are the total number of injuries and the number of affected people of each earthquake, so the calculation results are the total demand for the emergency rescue force of the earthquake. The next step is to use the number of injuries and the number of affected people per day after earthquake as input data, to calculate the change of the daily aviation emergency rescue force demand, and to realize the dynamic scheduling of the rescue aircraft after earthquake.

\section{Acknowledgment}

Thanks to the support of National key research and development plan 2016YFC0802601.

\section{References}

1. Kang Lijun. Application Research of Particle Swarm Optimization BP Neural Network on Emergency Resource Demand Forecasting [D], 2013, Lanzhou Jiaotong University

2. Li Lili. Research on demand forecasting for large-scale earthquake emergency rescue materials based on Grey Modeling Technology [D], 2013, Industrial and Commercial University Of Chongqing

3. Wang Zhengxin, Liu Sifeng. Forecasting Demand of the Disaster Emergency Supplies Based on Fourier-GM(1,1) Model, Systems Engineering, 2013(08): 60-64

4. Shuzhen Li, Alateng Tuya. Disaster Risk Research Literature on Statistics Analysis in China Journal 
Net, Journal of Risk Analysis and Crisis Response, Vol. 5, No. 2 (July 2015), 129-140

5. Fusheng Yu. Decision-Making Model in the Environment of Complex Structure Data, Journal of Risk Analysis and Crisis Response, Vol. 3, No. 2 (August 2013), 103-109

6. Nie Gaozhong. Models on rapid jugement for the emergent rescue needs during earthquake - by analysis on post-earthquake events, Resources Science, 2001(01): 69-76

7. Guo Jinfen, Zhou Gang. Research on Emergency Material Demand Forecast Method under Large-scale Earthquakes, Value Engineering, 2011. 30(22): 27-29

8. Lu, C., K. Ying and H. Chen, Real-time relief distribution in the aftermath of disasters - A rolling horizon approach. Transportation Research Part E: Logistics and Transportation Review, 2016(93): p. $1-20$.

9. Xu, X., Y. Qi and Z. Hua. Forecasting demand of commodities after natural disasters. Expert Systems with Applications, 2010. 37(6): p. 4313-4317.

10. Li Meixia, Che Haitao. Emergency Resource Dispatching Model and Algorithm, Operations Research and Management Science, 2011(03): 72-76

11. Wei Guoqiang, Wu Liang, Yang, Yongqing. Fuzzy programming model of emergency resources dispatching. Computer Engineering and
Applications, 2011,47(33):222-225

12. Shi Biao. A Two-stage Vehicle Scheduling Model of Transportation of Emergency Resources, Systems Engineering, 2012(07): 105-111

13. Junping Yan. The Spatial Symmetry Axis of Earthquake Hazard in China, Journal of Risk Analysis and Crisis Response, Vol. 3, No. 1 (May 2013), 59-64

14. Zhi Zhang, et al. Research Framework for Emergency Rescue of Disasters and Crises, Journal of Risk Analysis and Crisis Response, Vol. 2, No. 3 (November 2012), 173-177

15. Du Haijian. Study on Optimization of Allocation of Ambulance Helicopter in Earthquake Medical Relief. Helicopter Technique, 2014(01): 16-21

16. Liu, Y., et al. Robust optimization for relief logistics planning under uncertainties in demand and transportation time. Applied Mathematical Modelling, 2018(55):262-280.

17. Zdamar, L., E. Ekinci and B.K. Ükyazici, Emergency Logistics Planning in Natural Disasters. Annals of Operations Research, 2004(129): 217245.

18. Lu, G.B., L. Zdamar and A. Evik, An interactive approach for hierarchical analysis of helicopter logistics in disaster relief operations. European Journal of Operational Research, 2002(140):118 133. 